\title{
On the dynamics of subaqueous debris flows
}

\author{
Anders Elverhøi \\ University of Oslo $\cdot$ Oslo Norway \\ Carl B. Harbitz \\ Norwegian Geotechnical Institute • Oslo Norway \\ Panagiotis Dimakis \\ University of Oslo - Oslo Norway \\ Present address: Norwegian Water Resources and Energy Directorate - Oslo Norway \\ David Mohrig \\ University of Minnesota, - Minneapolis, Minnesota LISA \\ Present address: Exxon Production Research Co. - Houston, Texas USA \\ Jeff Marr, Gary Parker \\ University of Minnesota, • Minneapolis, Minnesota USA
}

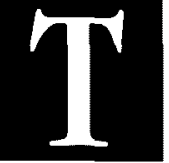

urbidity currents and debris flows represent the most prominent processes of sediment transport from the shallow shelf waters into the deep ocean. These gravity driven flows are capable of transporting large quantities of sediment over long distances (Middleton and Hampton, 1976; Hampton et al., 1996). Submarine debris flows are commonly thought to be laminar flows moving downslope as an agglomeration of particles held together by a thick sediment matrix composed mainly of silt, clay, and water (cohesive material). Turbidity currents are thought to operate at much lower sediment concentrations than debris flows, with the grains in a turbidity current held in suspension by turbulence. Turbidity currents have long been considered as the more important of the two. Consequently a number of deep sea fan models have been proposed based on the concept that turbidity currents transport gravel, sand and mud from shelf areas downslope through submarine canyons and channels and onto the basin plain. Recently, however, the importance of debris flows as a major sediment mass transfer mechanism have been demonstrated for the case of the NorwegianBarents Sea margin, where deep sea fans largely consisting of debris flows are found to be comparable in sediment volume to some of the world's largest turbidite fans (Elverhøi et al., 1998). Similar debris flows are also found on other glaciated margins (Aksu and Hiscott, 1992).
The classical concept of turbidity currents has also been challenged by Shanmugam and co-workers, among others (see for example, Shanmugam, 1997). In these studies, many sandstones previously interpreted to represent turbidites were claimed to represent the deposits of sandy debris-flow and slumps instead. The views of Shanmugam and co-workers, though not free of controversy, do nonetheless, raise several important conceptual questions pertaining to the relationship between the fundamental physical properties and the hydraulic behavior of a mobile sedimentary mass in the subaqueous environment. The problem is highly relevant to petroleum exploration because turbidity current deposits often have a sheet-like geometry with potential for lateral communication, whereas debris-flows often result in narrow, elongate, isolated depositional bodies.

Submarine debris flows can often display very long runout distances of up to more than $150 \mathrm{~km}$, even on very gentle slopes, i.e. less than $1^{\prime \prime}$. The long runout distance on these low angle fans represents a hydrodynamic enigma. In spite of increased viscous drag and reduced effective gravity due to buoyancy, subaqueous debris flows have often been inferred to have obtained significantly higher velocities and longer runout distances than their subaerial counterparts. The formation and flow behaviour of these debris flows thus represent important issues for understanding the construction of continental margins. 


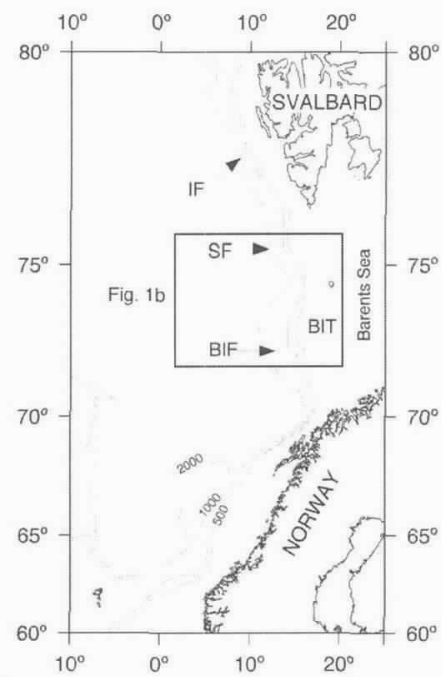

a.

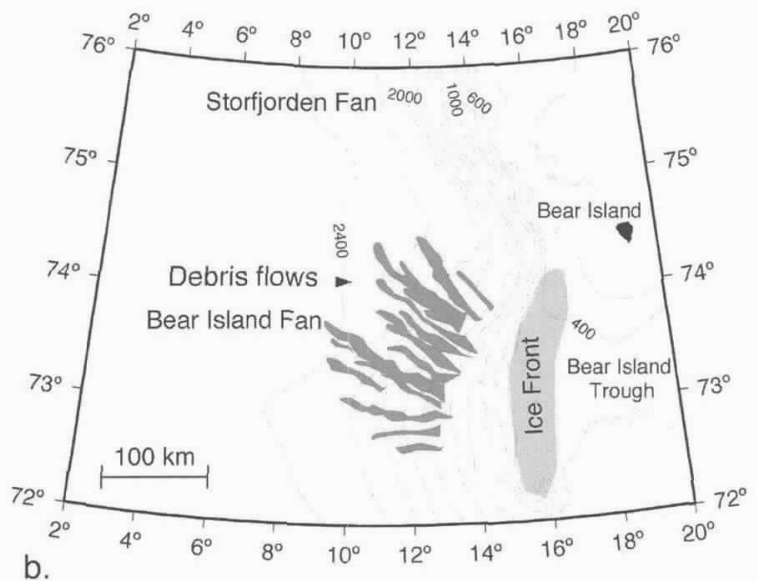

Figure 1. a) Bathymetric map showing the Svalbard-Barents Sea margin. b) The distribution of the debris lobes as recorded by GLORIA long range side scan sonar imagery is shown at the Bear Island Fan (modified from Dowdeswell et al., 1996). The debris flows $\left(10-30 \mathrm{~km}^{3}\right)$ form lobes with dimensions of 2-10 km wide, 10-50 m thick and 10-200 km long (Vorren et al., 1998). (BIF = Bear Island Fan, SF = Storfjorden Fan, IF = Isfjorden Fan). From Dimakis et al. (2000).

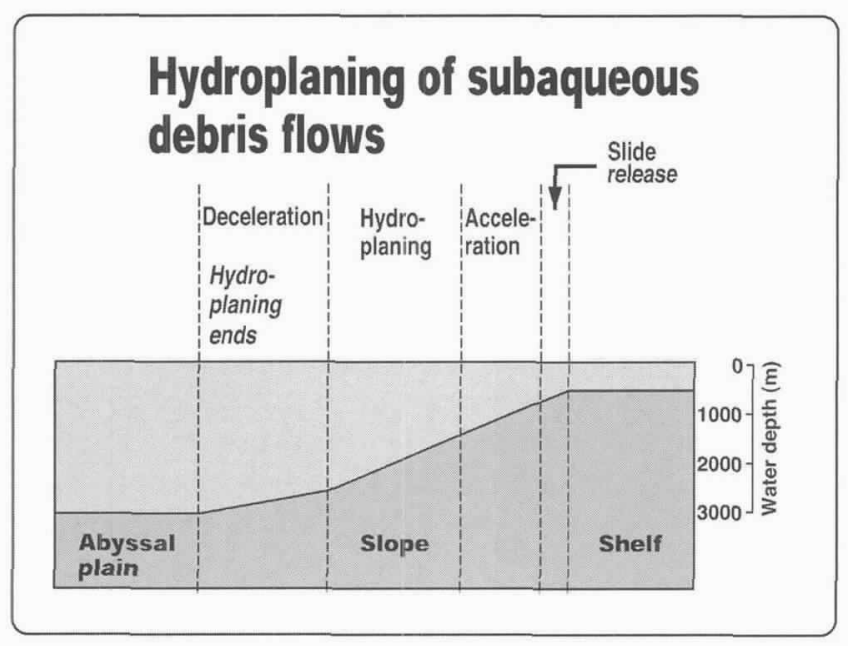

Figure 2. The dominant transport processes along different parts of a continental slope characterized by hydroplaning debris flows.
Submarine debris flows have mostly been described as Bingham fluids (see for example, Hampton et al., 1996). In simple shear, the stress-strain relation for a (viscoplastic) Bingham fluid in laminar flow implies that no deformation takes place until a specified yield stress is applied to the material, after which deformation is driven by the excess of the stress beyond this yield stress. The viscoplastic rheological relation dictates the division of the flow into a plug layer on top of a shear layer. Although the viscoplastic concept seems valid for clay-rich subaqueous debris flows, the very long runout distances on gentle slopes require low coefficients of friction or a low viscosity.

Recent laboratory experiments at St. Anthony Falls Laboratory, Univ. of Minnesota (SAFL) have, however, shown that the mobility of subaqueous debris flows may be at least partially due to hydroplaning (Mohrig et al., 1998, 1999). The presence of a basal layer of water can markedly reduce the bed friction, and so offers an explanation for the long travel distances and high velocities of many submarine flows on very gentle slopes. In addition, hydroplaning strongly mutes the role of debris rheology and often causes the head to run out ahead of the body. This in turn results in a thickness of deposit that is well below that associated with the yield strength of the flowing mass.

Hydroplaning also acts to suppress the remobilization of an antecedent debris deposit by an overpassing subaqueous debris flow. The lubricating layer inhibits the transmission of shear stress between the two debris layers. While hydroplaning does not provide a foolproof mechanism, it does offer a rheology-independent mechanism for greater runout distance, higher velocity and suppression of remobilization in the subaqueous environment that is both physically well founded and appealing in its simplicity.

A main objective of this paper is to present the current status of ongoing work on generation and flow behaviour of subaqueos high-density gravity mass flows (i.e. subaqueous debris flows). The study is largely based on field data from the continental margin west of Svalbard and the Barents Sea (Figure 1) combined with experimental studies at SAFL and analytical/numerical modelling. In the paper we focus on the following issues (see also Figure 2):

- Basic theory for the onset of hydroplaning

- Initial triggering mechanism of debris flows

- Parameter sensitivity analysis for debris flow dynamics

- Hydroplaning of muddy debris flows, theoretical descriptions and applications

Our findings are presumably relevant for other continental margins characterized by sediments with a high clay content forming viscoplastic sediment mass flow.

\section{Conditions for hydroplaning to occur}

For hydroplaning to occur, the flowing mass cannot devolve into a suspension. Simultaneously, the mass 
must be sufficiently mobile so as to reach the critical velocity for the onset of hydroplaning. If these conditions are fulfilled, hydroplaning occurs when the flow cannot displace the ambient fluid fast enough, i.e. approximately when the developing hydrodynamic stagnation pressure in front of the slide equals the submerged weight per unit area of the flowing mass.

As a result the head of the flow is lifted and the debris flow head is significantly deformed into a bulbous shape (Mohrig et al., 1998). This enables a wedgeshaped layer of water to intrude underneath the moving front. The intruding water layer reduces basal friction and increases the head velocity.

Debris flow heads show evidence of hydroplaning for the densimetric Froude number (that accounts for the buoyancy of the ambient fluid), $F r_{d}=U_{h}\left[\left(\rho_{h} / \rho_{w}-1\right) g h \cos \theta\right]^{-1 / 2}$ in excess of about 0.3 (Mohrig et al., 1998), where rw and rh are the densities of ambient water and flowing masses respectively, Uh is the velocity of the flow head with an average flow thickness $h, g$ is the acceleration of gravity, and $\theta$ is the slope inclination.

Huang and García (1999) present a model for a nonhydroplaning mudflow described as a Bingham fluid. This model illustrates that a non-hydroplaning Bingham mudflow of a constant mass volume only propagates a finite distance downslope from its source, with its thickness asymptotically approaching the yield thickness (the minimum thickness for the remolded mud to flow). The model no longer remains valid when the head velocity exceeds that for hydroplaning (Figure 3). It can be used, however, to study the evolution of a subaqueous debris flow to the point of onset of hydroplaning. For example, the ratio of the front velocity to the critical front velocity can be related to the critical front thickness for hydroplaning to occur as a

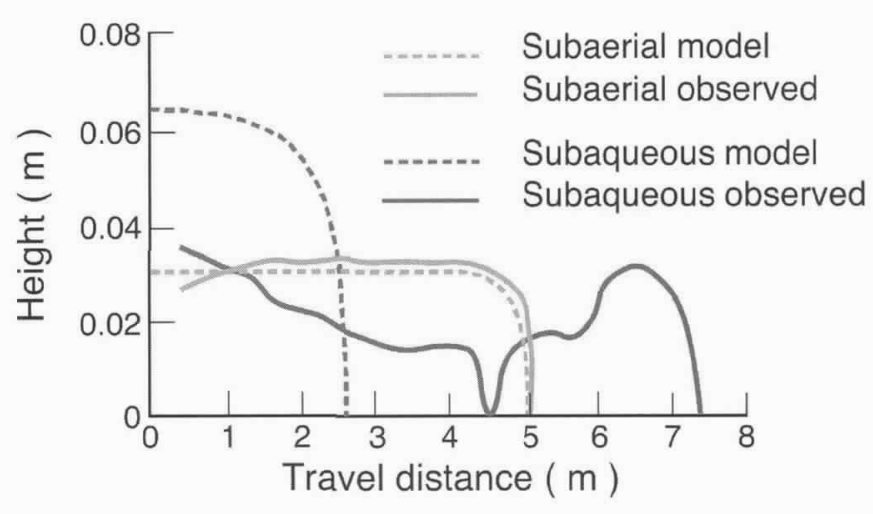

Figure 3. Deposit-depth profiles from submarine and subaerial debris flows. Laboratory experiments show that submarine debris flow has a head detached from the flow body and has a longer run out distance than a corresponding subaerial debris flow due to hydroplaning. The model predicts that subaerial debris flows form shallower deposits and have longer runout distances than submarine debris flows due to reduced effective gravity in the submarine environment (measurements from Mohrig et al., 1999) (Modified from Huang and Garcia, 1999). function of bulk density, slope inclination, yield stress, and viscosity.

\section{Initial triggering mechanism}

Deep-sea fans observed in high-latitude areas such as the Svalbard and eastern Canadian continental slope represent major depocentres of late Cenozoic sediments, and are interpreted to consist of stacked debris flows (Vorren et al., 1998). While the sediment volumes of these debris flows are large, the exact source of the sediment and its failure mechanism are not fully understood.

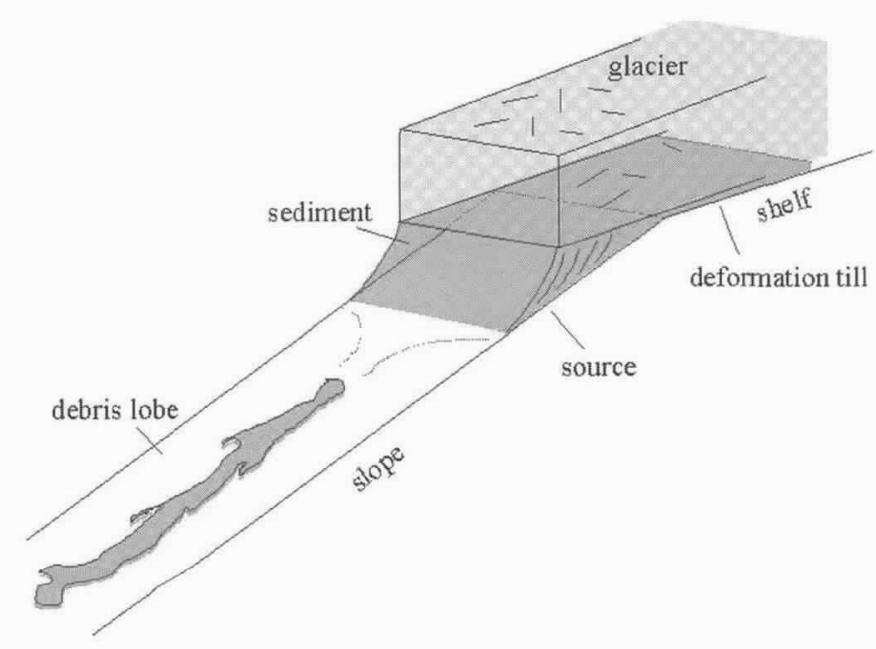

Figure 4. Conceptual diagram illustrating the sediment dynamics beneath and at the front of an ice stream draining the major troughs in high latitude areas. The deformation till under the ice stream is deposited in the iceproximal zone in a "conveyor belt" fashion. The sediments deposited in the ice-proximal zone eventually become unstable and generate debris flows. The annual sedimentation rate in the source area is in the range of 0.2-0.5 $m$ per year.

Seismic data from these fans reveal sediment layers of fairly uniform thickness without any major scarps or failure scars. This suggests a failure mechanism in which the sediment fails along a single planar surface.

The sediments forming the fans are interpreted to have been deposited as deformation till (Dowdeswell et al., 1996; Elverhøi et al., 1997). This mechanism of sedimentation is unique in the sense that the sediment is deposited without being suspended in the water column (Figure 4). This mode of deposition appears to have a significant impact on the mechanical properties of these tills, and these properties in turn determine the subsequent stability of the sediment on the slope. The high delivery rate (see Figure 4) causes a rapid build-up of excess pore pressure in the underlying sediment, which in turn causes the upper slope to fail despite the low slope angles that have been observed. An additional excess pore pressure may also result from the presence of an ice-sheet on the adjacent continental shelf (Mulder and Moran, 1995). Whether a debris flow will hydroplane or not, is not directly related to the trigger- 
ing mechanism, but rather to the subsequent mobility of the debris. However, excess pore pressures may originate free water and enhance the possibilities for hydroplaning.

The stability of a hypothetical ice-proximal depositional zone located at the shelf edge has been estimated for the Bear Island Fan (Dimakis et al., 2000). The geotechnical data used in the analysis come from two cores taken from two debris-flow lobes, one in the Bear Island Fan and the other in the Isfjorden Fan (Figure 1), (Mokkelbost, 1998). The analysis is based on the principle of infinite slope stability for a low angle slope, together with an excess pore pressure build-up due to high sedimentation rates.

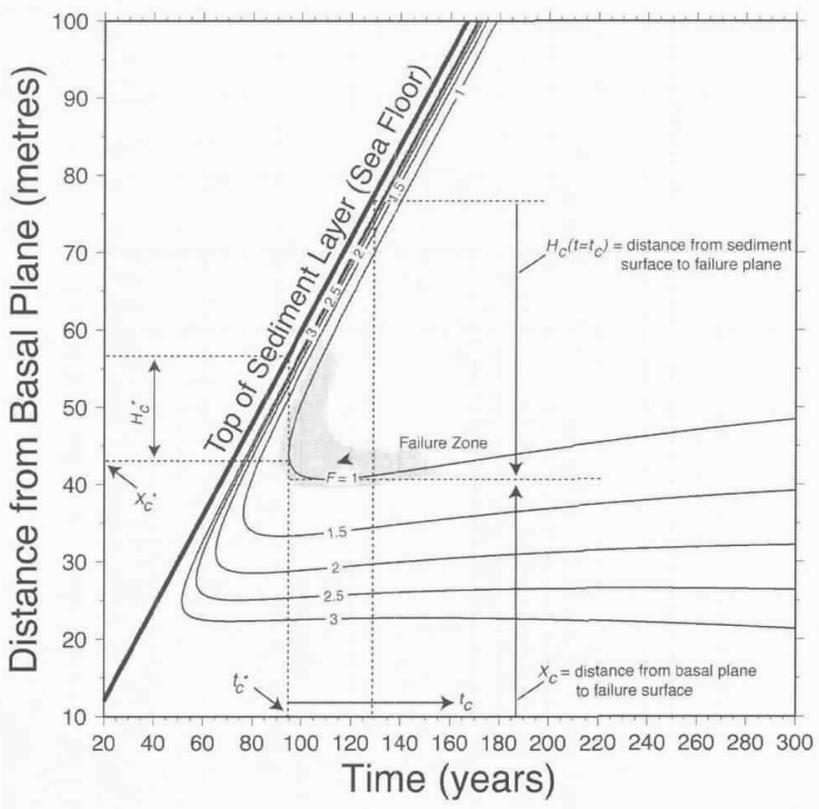

Figure 5. Safety factor contours obtained for the Bear Island Fan sample. The horizontal axis is time and the vertical axis is distance from the base of the sediment layer. Failure occurs when the safety factor obtains a value of 1.0, whereas higher values indicate greater stability. A line showing the position of the top of the sediment layer has also been included. The figure also illustrates the minimum critical time between failures $\left(t_{c}\right)$ and initial critical depth $\left(H_{c}\right)$, as well as the range of critical times and critical depths ( $t_{c}$ and $H_{c}$ ) existing within the possible failure zone. (From Dimakis et al., 2000).

The regenerative process of sediment conveyance due to glacial delivery and sheet-like failure suggested by an infinite slope analysis may well offer an explanation for the uniformly thick, layered deposits observed in the seismic data of the high-latitude fans off Norway and Svalbard. According to this model, sediment accumulates over a source area until it becomes unstable (Figure 5). Upon failure, the sediment above the failure plane, i.e. above the original surface of deposition moves downslope while the sediment below the failure plane remains and becomes the new surface of deposition (Figure 6). This cycle is repeated whenever the sediment becomes thick enough to exceed the failure criterion. In this way, a relatively uniform, layered deposit is formed by build-up of sediments in both the release and the depositional zones.

The analysis reveals that the sedimentation rate affects both the initial critical sediment thickness and the minimum critical time period between failures. The effect is more pronounced in the case of the minimum critical time period, which is reduced substantially with increasing sedimentation rates. An increase in slope angle causes more frequent slides, but the slides are of smaller sediment thickness. The cohesion intercept appears to be the most influential parameter in regard to slide frequency. The more cohesive the sediments the less frequent are the failures. The failures that do occur, however, are thick and remove much of the source area sediments. The parameter which least affects triggering is the friction angle.

\section{Parameter sensitivity analysis for debris flow dynamics}

A numerical model, BING, developed by Imran et al. (in review) can be employed to determine how failure volume, sediment rheology and slope inclination influence runout distance and deposit thickness in viscoplastic flow. BING is a depth-averaged, physically based continuum model that assumes that the failed sediment behaves according to a simple Bingham rheology. The model does not yet include hydroplaning.

Marr et al. (in review) have applied BING to debris
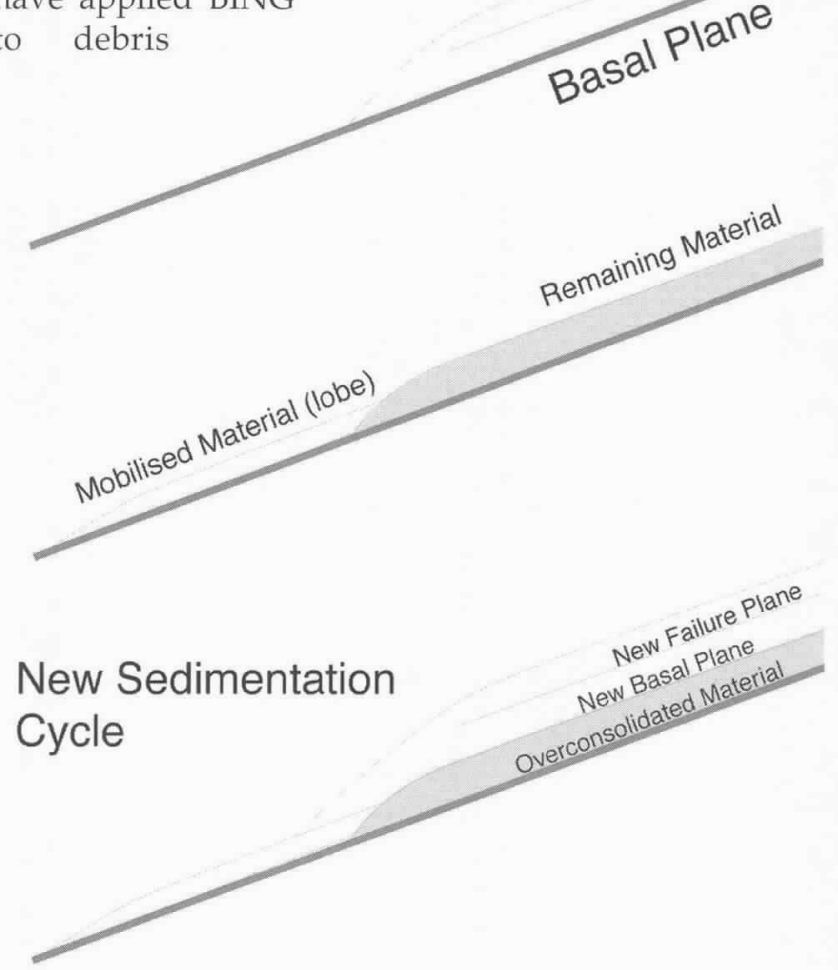

Figure 6. Illustration of slope failure under the infinite slope assumption. (From Dimakis et al., 2000). 
a)

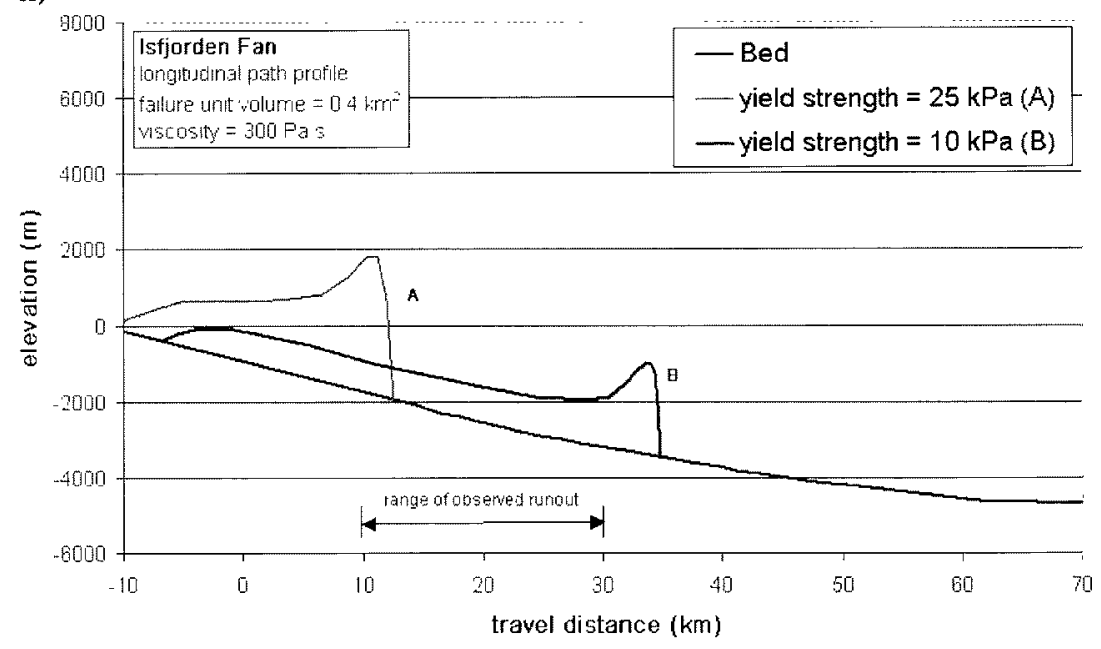

b)

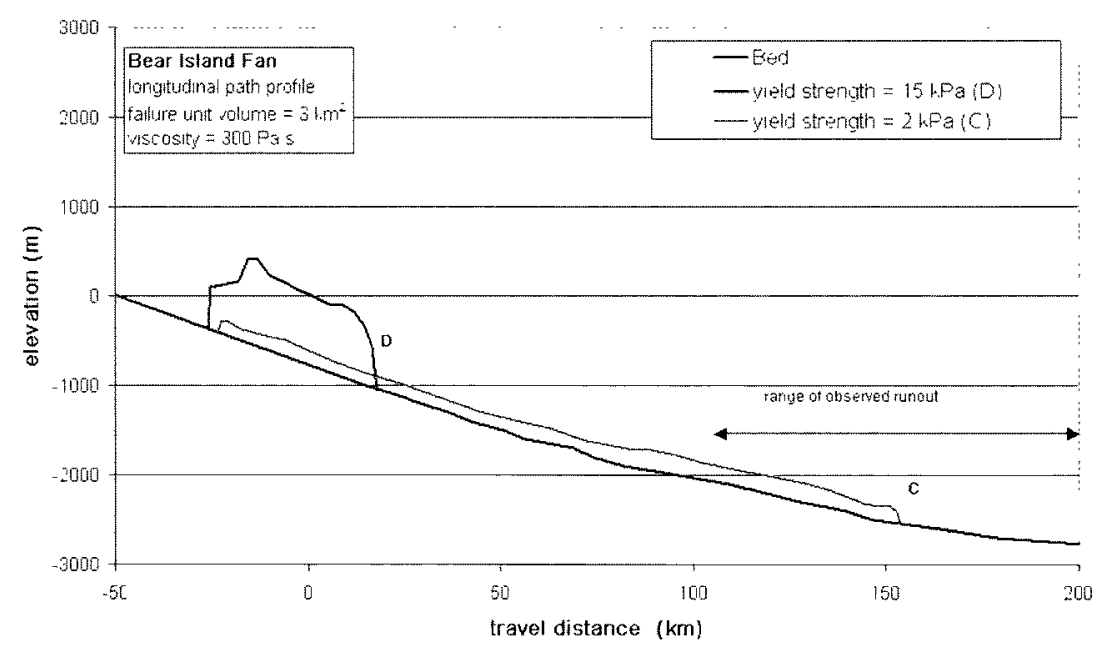

Figure 7. Deposit deptl and travel distance as a function of yidd strength: a) Isfiorden Fan (100x vertical exaggention); b) Bear Island Fan (10x vertical exaggeration). Note that the yield strength reflected by the obsered runout distance is one order of magnitude less than the yield strength reflected by the sediment itself. The long runout distance and relatizely thin deposit depth indicate hytroplaning, of. Figute 3.

flow runout. The study again focuses on the Bear Island and Isfjorden Fans. A relatively steep slope ranging from 3-4 degrees characterizes the Isfjorden Fan, while the Bear Island Fan has a measured slope of 0.2-0.5 degrees (Figure 7). The sediments on the two fans have very similar compositions. Sediment properties critical to the analysis include bulk density, failure volume, yield strength and dynamic viscosity. Three cases are examined:

- Isfjorden Fan simulation: vield strength determined by final deposit thickness, Figure 7a.

- Bear Island Fan simulation: yield strength determined by final deposit thickness, Figure $7 \mathrm{~b}$.

- Bear Island Fan simulation: realistic sediment rheology, Figure $7 \mathrm{~b}$.
The results can be summarised as follows:

- The volume of sediment failure strongly affects the final runout distance of the debris flow. If all other variables are the same, the failure with the largest volume will travel farthest.

- A failure on a high slope will flow farther than one with the same volume on a low slope.

- The higher the yield strength, the shorter the runout distance, resulting in thicker final deposits, Figure 7.

- The viscosity of the debris flow influences the runout most strongly in sediment with low yield strength. In sediment with high yield strength, variations in viscosity have little effect on runout. The general trend is for low-viscosity sediment to flow farther than highviscosity sediment.

The fact that BING does not include hydroplaning allows for inferences about its role. In the absence of hydroplaning it is found that sediment yield strength has a remarkable influence on final deposit geometry and flow velocity. Viscosity plays a lesser but still important role in this regard. Most importantly, however, the simulations for the Bear Island Fan reveal that the observed runout distance can only be achieved with a yield strength that does not agree with the observed sediment composition moving as a viscoplastic flow. It can be inferred that this lack of agreement is associated with hydroplaning, a condition that should have easily been reached according to the predictions of BING. The large runout distances of the debris lobes on the Bear Island Fan thus strongly suggest that hydroplaning of the debris flows influenced runout.

\section{Hydroplaning}

When hydroplaning is established, the moving debris flow head is substantially decoupled from its bed and, as shown in the experiments, runout distance and head velocity become independent of debris flow rheology (Mohrig et al., 1999). Once it is set up, the water film under the head associated with hydroplaning offers great resistance to being squeezed out and remains as a lubricating film between the two surfaces. Because the thickness of the water film is so small, the rate of strain and the stress due to viscosity are very large. This large 
stress can then generate a large pressure to support the hydroplaning debris above.

\section{Shear stress reduction}

Consider a subaqueous debris flow overriding an antecedent deposit. If the shear stresses are concentrated mainly in the deforming mud of the underlying deposit and/or a basal film of lubricating water, the overriding debris flow moves more or less as a rigid block. Hence, the shear stress reduction of a lubricating water film can be analyzed by equilibrium solutions of the resulting linear Couette flow in both the deforming mud and the water film, considering the slide as a rigid lid (Harbitz et al., in review).

\section{Lubrication theory}

A more detailed study of the internal conditions in the basal layer and the head velocity of the debris flow, Figure 8 , is provided by means of lubrication theory applied to a hydroplaning debris flow moving through a viscous fluid (Harbitz et al., in review). Three scenarios are analysed theoretically: (i) steady and completely hydroplaning flow; (ii) steady and partly hydroplaning flow; and (iii) non-steady partly hydroplaning flow.

The basis for the analysis is lubrication theory (Batchelor, 1967). In the standard analysis the total

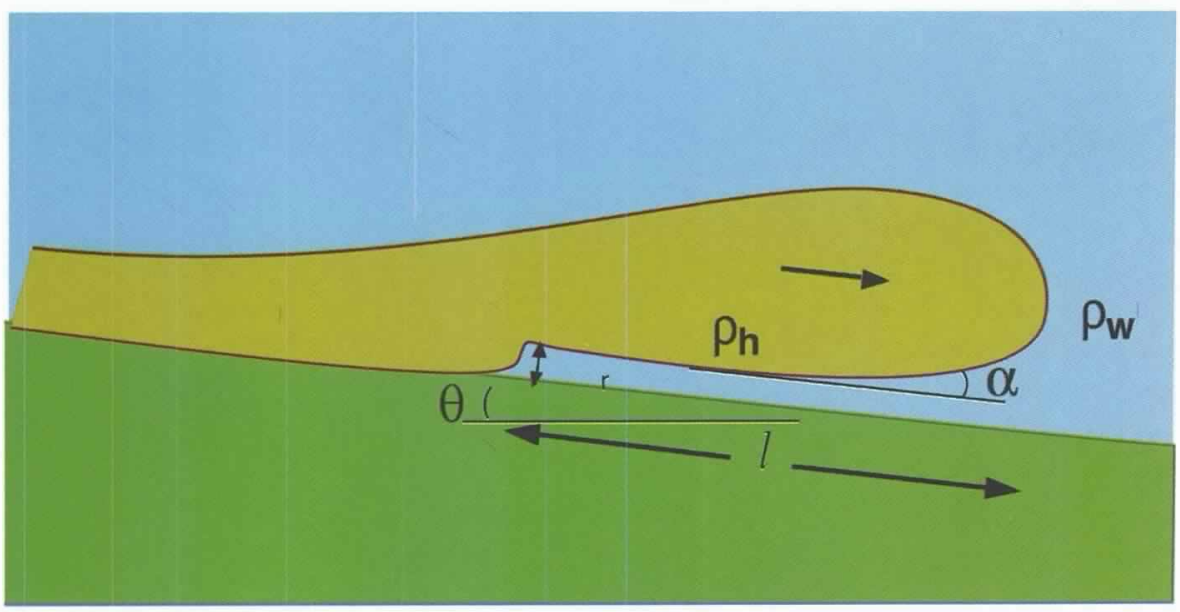

Figure 8. The lubricating water film underneath a partly hydroplaning debris flow. head. Application of the lubrication theory described above allows for an estimate of the thickness of the water film under a detached head in the event that its total mass can be determined from geological/geotechnical assessments.

If negligible vertical acceleration and tensile strength in the flow head are assumed, the pressure distribution in the water film can be shown to deflect the overriding thickness of the flow, thus determining the configuration of the head. In addition, the pressure distribution may be used for a geotechnical assessment of the extent of water penetration through the sliding body.

\section{Maintenance of the lubricating water film}

In the field where the debris flows are unconfined, the upstream point at which the debris flow mass is fully in contact with the underlying surface may be determined by side escape of lubricating water. This notwithstanding, Marr et al. (1998) have demonstrated experimentally that unconfined subaqueous debris flows hydroplane with about the same ease as their confined siblings. In addition, at the normally large dimensions of full-scale submarine flows the main part of the lubricating water must travel a relatively long distance in order to escape from the sides. Thus hydroplaning is likely to be effective over a long distance before side escape acts to suppress it. Depositional "fingering" pattern of debris lobes as described by Vogt et al. (1993), can be a result of certain areas of the flow locally moving faster (more lubricated) than others. The phenomenon is related to the side escape along the sides and finally to the cessation of hydroplaning in the front of the debris flow. In addition, the "fingers" may act as a lateral confinement for the rear part of the flow. In unconfined flows cessation of hydroplaning owing to lateral water escape may occur also for densimetric Froude number in excess of 0.3 .

normal force created by lubrication that acts to support the sliding body vanishes when the sliding body is not inclined relative to the underlying slope. It is worth noting, however, that this condition no longer holds when the average of the front- and rear-end pressures do not equal the hydrostatic pressure. That is, when non-hydrostatic effects are included, lubrication associated with hydroplaning can act to support the sliding body even when it is not inclined relative to the underlying slope.

As noted above, hydroplaning of the head can cause it to run out ahead of the body of the subaqueous debris flow. This can result in complete detachment of the
For both confined and unconfined flows the possibility of water percolation into the overriding debris flow must also be considered. Obviously, if the debris material is extremely impermeable the confined water film, once established, can be expected to be capable of maintaining hydroplaning of the debris material. Clay materials are generally considered to be impermeable for hydrogeological purposes due to the very low hydraulic conductivities (permeabilities) which characterize such porous materials. However, in this case the fact that clay materials are extremely impermeable is not sufficient to guarantee the maintenance of hydroplaning, because only a small amount of percola- 
tion will probably be enough to absorb the water film. Hence, the amount and rate of water penetration into the debris material needs to be studied.

As noted above, the model of Harbitz et al. (in review) uses the assumption of a large lateral extent of field-scale debris flows to approximate the sides as impermeable. This in essence reduces the problem to a one-dimensional one, in which the flow through a unit area column of the material is considered. The conditions for maintenance of hydroplaning are discussed in terms of dimensional and geotechnical aspects. Besides, the established total head gradient will most likely be enough to support the debris flow head. A subaqueous debris flow should, however, eventually cease to hydroplane owing to the reduction of bed slope in the streamwise direction. Hydroplaning is said above to occur for a densimetric Froude number above 0.3 , but once hydroplaning is established the densimetric Froude number may be below this value before a sufficient amount of water has escaped and hydroplaning ceases.

\section{Flow regimes}

The implications of hydroplaning in terms of the laminar/turbulent nature of the flow are determined by the Reynolds number. The calculated Reynolds numbers reveal that at field scale the flow head should likely generate a narrower wake than that expected at laboratory scale, thus causing a reduced pressure drag and hence a larger velocity. The water film can clearly be laminar at both scales, a condition that is necessary for the hydroplaning to be maintained.

\section{The use of laboratory and field-scale results}

The most scientifically valid and accurate way to increase the general knowledge of submarine mass flows is by linking field, laboratory and numerical observations. By maintaining equality in the appropriate non-dimensional numbers, it is possible to translate results between small-scale laboratory flows and largescale oceanic flows. Marr et al. (in review) have shown how distorted Froude modelling can be used to scale up laboratory results to equivalent field results. The experimental results obtained to date, however, do not cover a sufficiently wide range to allow for scale-up to any specified field condition. In addition, while such modelling allows for the scale-up of bulk parameters such as head velocity and deposit thickness, it does not allow for a scale-up of deposit microstructure at the level of the grains. This is because similitude cannot be maintained between laboratory and field realizations in terms of the ratio between flow thickness and grain size.

The theoretical description of hydroplaning presented above, however, is valid at both laboratory and field scale. As a first verification, the steady-state theory is applied below at laboratory scale and compared to the observations made by Mohrig et al. (1999). To illustrate the field scale implications of hydroplaning, calculations are also performed with representative parameter values from the Bear Island Fan along the Norwegian margin.

\section{Applications of the steady state theory of hydroplaning}

Applications of the theory presented above require a careful examination of the laboratory experiments and the full-scale observations in order to obtain realistic input parameter values. The values used in all example calculations are shown in Table 1.

\section{Laboratory scale calculations}

With the values presented in Table 1, the critical velocity for hydroplaning to occur according to the criterion by Mohrig et al. (1998), is $0.18 \mathrm{~m} / \mathrm{s}$ at laboratory scale. The terminal velocity of the hydroplaning debris flow head is $0.45 \mathrm{~m} / \mathrm{s}$. The applied material parameter values, slope inclination, and flow height further ensure that the front velocity exceeds the critical front velocity according to the criterion presented by Huang and García (1999).

\section{TABLE |}

Parameter values used in the example calculation, cf. Figure 8. Fr $r_{d}$ :Densimetric Froude number, $\rho h$ and $\rho$ w: density of flowing masses and ambient water, h: average thickness of the flow head, $\theta$ : slope inclination, $\mu_{m}$ and $\mu_{w}$ : dynamic viscosity of mud and water, $d_{r}$ : rear thickness of water film, $\alpha$ : angle that sliding body is inclined to the underlying slope, l: length of the hydroplaning part of the flow, $C_{D}$ : viscous drag coefficient, $L$ : thickness of deformable mud layer, $\epsilon$ : dimensionless thickness of water film.

\begin{tabular}{|c|c|c|c|c|c|c|c|c|c|c|c|c|c|}
\hline Scale & $\underline{\mathrm{Fr}_{d}}$ & $\underset{\mathrm{kg} / \mathrm{m}^{3}}{\rho h}$ & $\underset{\mathrm{kg} / \mathrm{m}^{3}}{\rho_{\mathrm{w}}}$ & $\begin{array}{l}h \\
\mathrm{~m}\end{array}$ & $\begin{array}{c}\theta \\
\text { deg. }\end{array}$ & $\underset{\mathrm{kg} /(\mathrm{ms})}{\mu_{m}}$ & $\underset{\mathrm{kg} /(\mathrm{ms})}{\mu_{\mathrm{w}}}$ & $\begin{array}{l}d_{r} \\
m\end{array}$ & $\begin{array}{c}\alpha \\
\mathrm{deg}\end{array}$ & $\begin{array}{l}\text { I } \\
\mathrm{m}\end{array}$ & $\underline{{ }^{C} D}$ & $\frac{L}{m}$ & $\epsilon$ \\
\hline Lab. & 0.3 & 1000 & 1600 & $0.06^{2}$ & 6.0 & $0.035^{4}$ & 0.0015 & $0.01^{2}$ & $0.05^{2}$ & $0.10^{2}$ & $0.30^{6}$ & $0.001^{5}$ & $0.1^{5}$ \\
\hline Full & 0.3 & 1000 & $1600^{\prime}$ & $20.0^{3}$ & $0.5^{3}$ & $0.035^{5}$ & 0.0015 & $0.01^{5}$ & $0.05^{5}$ & $1000^{5}$ & $0.01^{6}$ & $0.1^{5}$ & $0.1^{5}$ \\
\hline
\end{tabular}
1) Measured
2) Measured from video recordings by Mohrig et al. (1999)
3) From Laberg and Vorren (1995)
4) Deduced from Mohrig et al. (1999)
5) Assumed value
6) Determined by the Reynolds number and the thickness-to-length ratio of the debris flow head
7) Modified from Elverhøi et al. (1997) 
The laboratory experiments by Mohrig et al. (1999) revealed velocities in the range $0.48-0.65 \mathrm{~m} / \mathrm{s}$. This velocity is strongly dependent on the viscous drag coefficient, ${ }^{C} \mathrm{D}$, which is determined by the Reynolds number and the ratio of thickness to length of the debris flow head.

Finally, it is of interest to compare the shear stress computed by the rigid lid equilibrium solutions outlined above with the shear stress from lubrication theory. Again, with the values referred in Table 1, the two values are 6.7 and $5.1 \mathrm{~Pa}$, respectively. The rigid lid equilibrium solutions further reveal that the shear stress is reduced by a factor of 0.4 due to the lubricating water film.

The agreement between the calculations and the laboratory experiments by Mohrig et al. (1999) strongly supports the contention that the steady state theory of hydroplaning described above captures the essential elements of debris flow hydroplaning.

\section{Field scale calculations}

The corresponding field scale critical velocity is 3.3 $\mathrm{m} / \mathrm{s}$ according to the criterion by Mohrig et al. (1998), while the field scale terminal velocity is $14.3 \mathrm{~m} / \mathrm{s}$. Again the parameter values of Table 1 ensure conditions conducive to hydroplaning. At field scale the Reynolds number is much larger than at laboratory scale. In addition, the initiation mechanism differs and causes a much smaller ratio of thickness to length in the head, which implies that the pressure drag is of minor importance compared to skin friction. Both these aspects suggest the choice of a much smaller field scale viscous drag coefficient as indicated in Table 1.

The shear stress based on lubrication theory is $1.1 \mathrm{~Pa}$ at field-scale. The corresponding shear stress from the rigid lid equilibrium solutions is now 2.1 Pa. The ridged lid equilibrium solutions again reveal that the shear stress is reduced by a factor 0.4 by the lubricating water film.

\section{Future numerical simulations and objectives}

Applications of recent experimental and analytical insight on hydroplaning (Mohrig et al., 1998, 1999; Harbitz et al., in review) should be worked into numerical models. The goal of the numerical work should be to generate codes that simulate submarine debris flows from start to stop. This will help field geologists and engineers better understand and interpret depositional systems in which debris flows and turbidity currents are the dominant sediment transport modes.

The models for slope failure should describe the mechanical processes in the release of a stratified matrix with potential weak layers and have the capability of simulating block movement in response to retrogressive mass feeding through a narrow slide gate. Existing dynamics models for simulation of viscoplastic mass gravity flows in one horizontal dimension should be upgraded to include the concept of hydroplaning, as well as more advanced constitutive equations.

An enlargement of the models into two horizontal dimensions should be addressed in order to study the lateral distribution of sediment in an unconfined setting, and to fully describe the observed depositional patterns. This will help elucidate the concept of fingering, and the possible lateral dissipation of water during the motion. Owing to the complexity of the constitutive equations and the resulting flow pattern, an extension to two horizontal dimensions is not a trivial task, and requires an accurate and stable code. At present, the latter requirement is not fully obtained even with only one horizontal dimension.

Forthcoming laboratory experiments should reveal much-needed information on shear stress and erodibility of debris flow heads. The experiments should include a rigorous analysis of the scaling between field and laboratory flows that allows the observations of the experiments to be applied to field-scale depositional basins.

A sensitivity analysis with different rheological parameters and descriptions should be emphasized to analyze how sediment rheology and hydroplaning influence flow behavior and depositional geometry. A fundamental goal should be to establish criteria determining whether a subaqueous mass gravity flow will evolve into a turbidity current or a debris flow, and additionally whether a debris flow will hydroplane or not. The analysis should be closely related to field observations as well as laboratory experiments.

\section{Acknowledgements}

This work was funded as part of the E.C. Marine Science and Technology (MAST III) programme ENAM II, the SEABED project and the Marine Geology and Geophysics program (STRATAFORM project) of U.S. Office of Naval Research. The authors are indebted to the two referees, M. García and L. Pratson, for valuable criticism and comments.

\section{REFERENCES}

Aksu, A.E. and R.N. Hiscott, 1992: Shingled Quaternary debris flow lenses on the north-east Newfoundland Slope. Sedinentology, 39, 193-206.

Batchelor, G.K. 1967: An introduction to fluid dynamics. Cambridge University Press, $615 \mathrm{pp}$.

Dimakis, P., A. Elverhøi, K. Høeg, A. Solheim, C.B. Harbitz, J.S. Laberg, T.O. Vorren and J. Marr, 2000: Submarine slope stability on high-latitude glaciated Svalbard-Barents Sea margin. Mar. Geol., 162, 303-316.

Dowdeswell, J.A., K.H. Kenyon, A. Elverhøi, J.S. Laberg, F.J. Hollender, J. Mienert and M.J. Siegert, 1996: Large-scale sedimentation on the glacier-influenced Polar North Atlantic margins: long-range sidescan sonar evidence. Geophys. Res. Letters, 23, 35353538.

Elverhøi, A., H. Norem, E.S. Andersen, J.A. Dowdeswell, I. Fossen, H. Haflidason, N.H. Kenyon, 
J.S. Laberg, E.L. King, H.P. Sejrup, A. Solheim and T. Vorren, 1997: On the origin and flow behaviour of submarine slides on deep-sea fans along the Norwegian-Barents Sea continental margin. GeoMarine Letters, 17,119-125.

Elverhøi, A., R.L. Hooke, and A. Solheim, 1998: Late Cenozoic erosion and sediment yield from the Svalbard-Barents Sea region: Implications for understanding erosion of glacierized basins. Quaternary Science Revieus, 17, 209-241.

Hampton, MA., H.J. Lee and J. Locat, 1996: Submarine landslides. Rev. Geophlys., 34, 33-59.

Harbitz, C.B., A. Elverhøi, D. Mohrig, G. Parker and P. Dimakis, in review: Hydroplaning of muddy debris flows: Theoretical descriptions and applications on high latitude glacigenic deep-sea fans. J. Grophy. Res.

Huang, X. and M.H. García, 1999: Modeling of nonhydroplaning mudflows on continental slopes. Mar. Geol., 154, 131-142.

Imran, J., P. Harff and G. Parker, in review: A numerical model of submarine debris flows with graphical user interface. Computers and Geosciences.

Laberg, J.S. and T.O.Vorren, 1995: Late Weichselian submarine debris flow deposits on the Bear Island Trough Mouth Fan. Mar. Gcol., 127, 45-72.

Marr, J., P. Harff, G. Shanumgan and G. Parker, 1998: Experiments on unconfined subaqueous debris flows. Eos, Transactions, 79(45), OS22D-05.

Marr, J., A. Elverhøi, P. Harff, J. Imran, G. Parker and C.B. Harbitz, in review: Numerical simulation of mud-rich subaqueous debris flows on the glacially activated margins of the Svalbard-Barents Sea. Journal of Sedinentary Research

Middleton, G.V. and M.A. Hampton, 1976: Subaqueous sediment transport and deposition by sediment gravity flows. In: Marine sediment transport and environmental management. D.J. Stanley and D.J.P. Swift (eds.); John Wiley \& Sons. New York, 197-218.

Mohrig, D., A. Elverhøi, and G. Parker,. 1999: Experiments on the relative mobility of muddy subaqueous and subaerial debris flows, and their capacity to remobilize antecedent deposits. Marine Geology $154,117-129$.

Mohrig, D., K.X. Whipple, M. Hondzo, C. Ellis, and G. Parker, 1998: Hydroplaning of subaqueous debris flows. Geol. Soc. Am. Bull. 110, 387-394.

Mokkelbost, K.H. 1998. Submarine Slides: Laboratory testing of marine sediments from the Norwegian continental margin. Norwegian Geotechnical Institute, Report 522091-1, 13 pp.

Mulder, T. and K. Moran, 1995: Relationship among submarine instabilities, sea level variations, and the presence of an ice sheet on the continental shelf: An example from the Verrill Canyon Area, Scotian Shelf. Paleoceanography, 10, 1, 137-154.

Shanmugam, G., 1997: Deepwater exploration; conceptual models and their uncertainties. Bulletin - Houston Geological Society, 39; . 13.

Vogt, P.R., K. Crane and E. Sundvor, 1993: Glacigenic mudflows on the Bear Island submarine fan. EOS, Transactions of the American Geoplysical Union, 74, 449, 452-453.

Vorren, T.O., J.S. Laberg, F. Blaume, J.A. Dowdeswell, N.H. Kenyon, J. Mienert, J. Rumohr and F. Werner, 1998: The Norwegian-Greenland Sea continental margins: morphology and Late Quaternary sedimentary processes and environment. Quaternary Science Review, 17, 273-302. 